\section{ГОСУДАРСТВЕННЫЕ МЕРЫ ПО РЕШЕНИЮ СОЦИАЛЬНЫХ ПРОБЛЕМ СОВРЕМЕННОЙ МОЛОДЕЖИ МОНГОЛИИ}

\begin{abstract}
Аннотация:
Настоящая статья посвящена сущности и содержанию социальных проблем одной из самых многочисленных социально-демографических групп современного монгольского общества - молодежи. Автор исследует государственные меры социальной защиты этой части населения, государственные программы поддержки и содействия развитию и самореализации молодых людей. Приводятся статистические данные Управления статистики Монголии, Организации Объединенных Наций, а также описание наиболее актуальных проблем социального и культурного характера, существующих в среде современной монгольской молодежи, и способов их решения. Кроме того, раскрываются отличительные особенности социальных проблем указанной группы общества, анализируются негативные тенденции в поведении и жизнедеятельности молодого поколения в условиях нестабильной реализации государственной политики по социальной защите молодежи Монголии.
\end{abstract}

Ключевые слова:

молодежь, Монголия, социальные проблемы, безработица, государственные программы, участие молодежи.

\section{STATE MEASURES TO ADDRESS THE SOCIAL PROBLEMS OF CONTEMPORARY YOUTH IN MONGOLIA}

Summary:

The paper deals with the essence and content of social problems of one of the most numerous social and demographic groups of contemporary Mongolian society, i.e. the youth. The author reveals the government social protection measures for the modern youth, the state programs for support and promotion of development and self-realization of young people. The research provides the statistical data of the Statistical Office of Mongolia, the United Nations, as well as describes the most urgent social and cultural problems of Mongolian youth and the ways to address them. In addition, the distinctive features of the social problems of the above-mentioned group are revealed, the negative trends in the behavior and functioning of the younger generation are analyzed in the context of the unstable implementation of the state policy on social protection of the contemporary youth of Mongolia.

Keywords youth, Mongolia, social problems, unemployment, government programs, youth participation.

Во многих странах мира молодежь считают поколением будущего, способным определить судьбу государства. Для поддержки молодого поколения реализуются политические меры и государственные программы, направленные решение проблем, с которыми молодые люди сталкиваются в современной жизни.

По данным на конец 2014 г. из 198 стран мира в 122 приняты государственные программы по поддержке молодежи [1]. В Монголии 38,5 \% граждан составляют молодые люди в возрасте 1534 лет, они являются наиболее многочисленной группой населения по сравнению с остальными возрастными категориями [2]. Поэтому самыми актуальными вопросами для монгольского общества на текущий момент можно назвать определение общих проблем, с которыми сталкивается молодежь; усиление государственной поддержки в этой сфере; увеличение доли участия молодого поколения в государственных делах; удовлетворение основных потребностей молодых семей.

В связи с изложенным можно выдвинуть следующие гипотезы. Во-первых, неоднозначный научный подход к пониманию и анализу социальной поддержки молодежи не позволяет выявить основные направления государственной молодежной политики в современном монгольском обществе. Во-вторых, господдержка молодежи развивается в соответствии с общемировыми тенденциями, однако ее уровень не обеспечен в достаточной степени нормативно-правовой, организационно-управленческой и технологической базой.

Степень грамотности в Монголии довольно высока по состоянию на 2010 г., у граждан в возрасте 15-24 лет она составляет 98,5 \%. Доля учащихся 15-19 лет резко возросла с 47,0 \% в 2000 г. до 79,0 \% в 2010 г. В 2010 г. число специалистов с высшим образованием увеличилось до 22,0\%. Исходя из данных показателей, видно, что в Монголии доступ к образованию открыт, но согласно докладу Всемирного экономического форума страна заняла 76-е место из 122 государств мира [3].

Доля молодых людей с ограниченными возможностями, реализовавших потребности в получении образования, в возрасте 15-17 лет составляет 47-55 \%, 18-19 лет - 29-39, 20-24 года 14-20, 25-29 лет - 5-8 \%. Этот показатель свидетельствует о недостаточности обеспечения условий получения образования на всех ступенях системы обучения [4]. 
Согласно данным, представленным Министерством здравоохранения в 2013 г., молодежь подвержена главным образом заболеваниям мочеполовой и пищеварительной систем, травмам разной степени тяжести, пищевым отравлениям, респираторным, неврологическим, сердечно-сосудистым заболеваниям, болезням верхних дыхательных путей [5]. Кроме того, в 2010-2012 гг. смертность людей в возрасте 15-29 лет составила 17,2 \% от общей смертности населения [6]. К ее причинам можно отнести неправильный и малоподвижный образ жизни, злоупотребление алкоголем, нездоровое питание, отсутствие возможности покупать качественную и полезную пищу, ожирение, низкий уровень полового воспитания, слабая информированность о правильном питании и здоровом образе жизни, профилактике заболеваний [7].

Правительство Монголии в 2013 г. приняло национальную программу под названием «Трудоустроенный обеспеченный монгольский гражданин». Согласно опросу, проведенному в том же году, безработные молодые мужчины в возрасте 15-29 лет составляли 46,2 \% населения, молодые женщины - 36,9%. В 2014 г. число нетрудоустроенной молодежи уменьшилось до 43,6 и 41,6 \% соответственно [8]. Уровень безработицы снижается относительно показателей предыдущих годов, но почти половина представителей молодого поколения по-прежнему остается безработной. Согласно опросу ООН 2013 г. 62,6 \% молодежи Монголии трудоспособного возраста не имели достаточного дохода для удовлетворения повседневных потребностей [9]. Это свидетельствует о необходимости принятия всеобъемлющего комплекса мер в целях координации деятельности правительственных учреждений и неправительственных организаций в этой области.

Один из приоритетов, существующих у молодежи в целом и молодых семей в частности, приобретение собственного жилья. Представители молодого поколения, участвовавшие в опросе 2010 г., первоочередной задачей считали именно это [10]. Согласно исследованиям Монгольской федерации молодежи 62,3 \% молодых людей живут с родителями, в съемных квартирах, домах родственников или жилье, предоставляемом им от работы [11]. Правительство Монголии в 2013 г. приняло программу «Общие положения регулирования ипотечного кредитования», направленную на улучшение положения в данной области.

Кроме того, важно расширить роль молодежи в социальных процессах и развитии общества. Согласно результатам опроса 2011 г. 86,3 \% респондентов считают, что участие молодого поколения в государственных делах имеет большое значение [12]. Это показывает, что молодые люди стремятся внести вклад в развитие страны и принятие важных решений. По-прежнему существует потребность в создании эффрективных механизмов поддержки голоса молодежи во всех социально значимых секторах, поощрения их инициатив, реального участия в деятельности молодежных неправительственных организаций.

Необходимо обеспечить молодежи качественное образование, достойные условия труда, работу в безопасной окружающей среде, защиту здоровья, бесплатные медицинские услуги, равноправие мужчин и женщин в области политических, экономических, социальных, культурных и семейных отношений. В настоящее время наблюдаются нарушения прав молодежи в разных сферах. Отсутствие исследований и недостаток статистических данных о несоблюдении прав молодых людей создают дополнительные трудности при решении данной проблемы. Неуважение и дискриминация свидетельствуют о низком уровне моральных ценностей и правовой грамотности молодого поколения. Следует разрабатывать мероприятия, направленные на обеспечение прав молодых людей и предоставление им юридического образования и правового консультирования.

Сегодня молодые граждане с ограниченными возможностями, сироты и бездомные, беспризорные дети, несовершеннолетние, работающие в недетских условиях труда, молодые семьи нуждаются в социальной поддержке. Молодым заключенным в местах лишения свободы в особом порядке требуется государственная помощь. В связи с этим возникает острая необходимость в разработке целенаправленной политики и программ социальной поддержки неблагополучных слоев населения.

Таким образом, комплексное решение правительством проблем, с которыми сталкивается молодежь, должно заключаться в подготовке и реализации программ социальной молодежной политики, способствующих реальному участию данной возрастной группы во всех социальных процессах Монголии. Возникает необходимость проведения регулярных исследований, охватывающих большинство молодых людей, с тем чтобы эфффективно выявлять проблемы в этой сорере, осуществлять политическую деятельность, отслеживать и оценивать результаты, а также вносить изменения [13].

Министерство развития населения и социальной защиты, Фонд ООН, организации «Программа развития ООН», «Всемирная перспектива Монголии», НПО «Монгольская молодежная ассоциация», НПО «Форум открытого общества» а также Институт социологии и философии Академии наук Монголии провели исследования мнений молодежи. Согласно их результатам попрежнему существует потребность в расширении и поддержке неправительственных объединений и научных центров, изучающих проблемы молодого поколения. 
Будучи гражданами развивающейся страны, молодые люди Монголии нуждаются в хорошем образовании, трудоустройстве, увеличении доходов, собственном жилье, обеспечении участия в государственных делах, политической и социальной сферах. Правительство Монгольской Народной Республики приняло следующие нормативные акты и программы, направленные на удовлетворение нужд данной возрастной группы: «Комплексная стратегия национального развития в области развития: Декларация тысячелетия» (2008), «Политика правительства Монголии в области развития населения» (2004), «Политика развития семьи Монголии» (2003), «Жилищная политика правительства», «Национальная политика в области фризической культуры и спорта» (2009), «Государственная политика в области общественного здравоохранения» (2001), Национальная программа поддержки молодежи (2006), Национальная программа занятости монгольских граждан (2013), Правительственная программа реабилитации здоровья на 2012-2016 гг. Эти меры частично охватывают проблемы молодежи, но не обеспечивают комплексное решение всех социальных задач в сфере социальной поддержки молодежи. В качестве исключения можно назвать лишь один документ - Национальную программу содействия развитию молодежи [14]. Тем не менее реализация программы и механизмов мониторинга ее результатов, распределение роли государственных учреждений не были прозрачными, а фрактического фринансирования было недостаточно для полноценного внедрения всех ее положений.

В качестве еще одной проблемы выступает то, что государственные служащие и социальные работники, которые предоставляют общественные и социальные услуги, часто сменяются на должностях ввиду нестабильности и дефицита знаний и информации об осуществляемой ими деятельности. Это свидетельствует о неоднозначном научном подходе к пониманию и анализу социальной поддержки молодежи, не позволяющем выявить основные направления государственной молодежной политики в современном монгольском обществе.

В последнее десятилетие у монгольской молодежи наблюдается стремление во что бы то ни стало получить образование, иметь дипломы и сертификаты, которые, по их мнению, позволят найти перспективную работу и обеспечат беззаботное будущее. Между тем эта тенденция обусловливает появление множества учебных заведений с сомнительными репутацией и качеством предоставляемого образования. В настоящее время в Монголии насчитывается 162 университета и колледжа, а количество студентов составляет 150,3 тысячи человек.

Оказание только материальной помощи молодым людям, нуждающимся в социальной поддержке, в том числе лицам с ограниченными возможностями, не может комплексно решить проблемы, с которыми сталкивается молодежь в повседневной жизни. Молодые монголы, обладая внушительными внутренними ресурсами, не имеют опыта их реализации, поэтому они нуждаются в надежной защите и поддержке прежде всего со стороны государства. Государственная деятельность в данной сфере не обеспечена требуемой нормативно-правовой базой, определяющей направление, степень и характер социальной поддержки монгольской молодежи, хотя и развивается в соответствии с общемировыми тенденциями. В связи с этим обостряется необходимость социологического анализа существующих мер и форм социальной поддержки молодого поколения, а также решений, обозначенных в госпрограммах, в частности Национальной программе содействия развитию молодежи.

Таким образом, решение социальных проблем представителей молодого поколения монголов должно обеспечиваться управленческими, организационными и технологическими средствами в комплексе. Также следует учитывать национальные особенности, что будет способствовать повышению эффрективности социальной поддержки молодежи на разных этапах ее социализации. В связи с этим необходим мониторинг реализации программ социальной поддержки молодых людей и их жизненных планов. Это позволит придерживаться приоритетных направлений политики в данной области, оптимизировать самореализацию молодежи и повышать эффективность реализации ее индивидуального и социального потенциала.

\section{Ссылки:}

1. The state of youth policy in 2014 [Электронный pecypc] : report. URL: http://www.youthpolicy.org/library/wp-content/uploads/library/2014 State Youth_Policy 2014_En.pdf (дата обращения: 11.01.2018).

2. Доклад о человеческом развитии : программа развития ООН. Улан-Батор, 2014. Гл. 3. На монг. яз.

3. Там же. Гл. 3, ч. 1, 4, 7, 12.

4. Там же. Ч. 9.

5. Там же. Ч. 3

6. Там же. Ч. 2.

7. Там же. Ч. 5,6

8. Там же. Ч. 13.

9. Рекомендации к государственной политике о развитии молодежи. Министерство развития населения и социальной защиты ; ЮНФПА. Улан-Батор, 2013. Ч. 49. На монг. яз.

10. Там же. Ч. 50 .

11. XXI век- монгольская молодежь : базовое исследование Федерации молодежи Монголии. Улан-Батор, 2011. На монг. яз.

12. Там же.

13. Доклад ... Ч. 1

14. Draft Mongolian Youth Policy Framework. Berlin, 2014. Pt. 39. 


\section{References:}

Draft Mongolian Youth Policy Framework 2014, Berlin, Pt. 39. lian).

Human Development Report: United Nations Development Program 2014, Ulaanbaatar, Ch. 3, pt. 1-7, 9, 12-13, (in Mongo-

Recommendations for the state policy on the youth development. Ministry of the Population Development and Social Protection 2013, UNFPA, Ulan-Bator, Part 49, 50, (in Mongolian).

The 21st century - Mongolian youth: a basic study of the Mongolian Youth Federation 2011, Ulaanbaatar, (in Mongolian).

The state of youth policy in 2014: report 2018, viewed 11 January 2018, <http://www.youthpolicy.org/library/wp-content/uploads/library/2014_State_Youth_Policy_2014_En.pdf>. 